\title{
Effect of Topical Nasal Decongestants on Nasal Peak Flow Rates in Adults Suffering from Acute Sinusitis
}

\author{
Santhosh Kumar Rajamani ${ }^{1}$
}

\section{Introduction:}

\section{$\underline{\text { ABSTRACT }}$}

In this research we studied the effect of topical nasal decongestant (Xylometazoline 0.1\% solution) on serial measurements of nasal peak flow rates in a cohort of patients who were suffering from acute sinusitis.

Materials and Methods:

A population of 90 patients were chosen from our regular out-patient clinics who were suffering from acute sinusitis based on a clinical diagnostic criterion. A baseline Nasal Peak Flowmetry was done. This was followed by a common decongestant (Xylometazoline 0.1\% solution) spray application. Subsequently Nasal Peak Flowmetry was done after 10, 25, 60, 120, 240 and 360 minutes and the readings were plotted and analysed.

Result:

From the AUC Curves it can be inferred that maximum decongestant action of Xylometazoline $0.1 \%$ solution is seen 1 hour after application and the rise in decongestion reaches a plateau by 2 hours. Readings almost return to baseline a good 6 hours post decongestion.

\section{Conclusion:}

Patients who are prescribed Xylometazoline $0.1 \%$ solution are advised that maximum relief from congestion would be obtained around 1 to 2 hours after application. In addition, Surgeons who use Xylometazoline 0.1\% solution for nasal packing must proceed with the surgery within 1 hour of application of the pack to obtain maximum haemostatic and decongestant benefit of this drug.

Keywords:

Sinusitis; Nasal Obstruction; Nasal Decongestants; Xylometazoline

$\mathrm{N}$ asal disease is a significant contributor to the suffering of millions daily. Significant nasal obstruction due to deviated nasal septum contributes to an entire gamut of nasal diseases like sinusitis. ${ }^{1}$

Expiratory Peak Flowmetry is a widely used test for quantification of airway obstruction in Asthma. Nasal Peak Flowmetry is a rapid test in diagnosis of functional impairment of nose in various disease conditions. This test has been applied in diagnosis and follow-up of Allergic Rhinitis. ${ }^{1}$ In this original research we used this novel

1 - Department of ENT, BLK Walawalkar Rural Medical college, Maharashtra.

\section{Corresponding author:}

Dr Santhosh Kumar Rajamani

email: minerva.santh@gmail.com investigative tool for diagnosis as Nasal Peak Flowmetry is a non-invasive, inexpensive, rapid and accurate test in diagnosis of nasal obstruction and impaired air-flow in the nose. NPF is a simple tool for objective assessment of Nasal patency. ${ }^{2}$ Maximum air flow is measured while blowing out of the nose or Expiration called as Nasal Peak Expiratory Flow (NPEF) and while deep breathing air into the nose or Inspiration called as Nasal Peak Inspiratory Flow (NPIF). Nasal Peak Inspiratory Flow (NPIF)is more accurate than Nasal Peak Expiratory Flow (NPEF) $)^{2}$. NPIF is more rapidly done, has a better validation and higher quantification. ${ }^{3}$

The disadvantages of this investigation are: (a) the presence of secretions and mucus can obstruct and reduce the peak air flow, (b) the test is less sensitive than Rhinomanometry or Acoustic rhinometry ${ }^{2}$ and (c) the mask has to be sterilized after each use. ${ }^{3}$ 


\section{Materials and Methods}

This was a cross-sectional descriptive epidemiological type of study. Research was done in a hospital Otorhinolaryngology clinic, and cases were analysed from cohort of patients presenting to the author with a variety of nasal complaints.

A population of 90 patients were chosen from our regular out-patient Otorhinolaryngology clinics who were suffering from acute sinusitis. 120 age matched healthy adult volunteers were also chosen as controls. Children below the age of 14 years and elderly above 70 years of age were excluded from the study. Patients who were toxic and sick were excluded. Verbal and written consent was obtained before and after measuring Nasal Peak flow rates. Nasal Peak Inspiratory Flow Rate was measured before and after packing/ spraying nose with Decongestant. ${ }^{4}$

Diagnostic Inclusion Criteria for Sinusitis: ${ }^{5}$

- Duration of complaints less than 4 weeks

- Fever, cough, fatigue, reduced sense of smell, purulent nasal discharge

- Maxillary dental pain, Ear fullness/pressure

- History of upper respiratory tract infection (common cold) in the preceding10 days

- Diagnostic nasal endoscopy shows purulence in the nasal cavity or posterior pharynx

- Computed tomography (CT) - Sinus mucosal thickening more than $5 \mathrm{~mm}$, Obstruction of osteomeatal complex (OMC)

Nasal Peak Flowmetry was done using Mini-Wright Peak Nasal Flowmeter device and patients were asked to put maximum effort inspiration and expiration. ${ }^{5}$

Patients were excluded from the study if they had a history of asthma or cardiac arrhythmias, or if they were taking any medications that could interfere with the PNF readings. I also excluded patients more than 70 years or below 14 years.

Xylometazoline acts on alpha-adrenergic receptors in the nasal mucosa and nasal vasculature to produce vasoconstriction, resulting in reduced blood flow and reduced nasal congestion, thus producing relief from nasal obstruction in sinusitis. ${ }^{7}$ In addition, it reduces the mucosal congestion of sinuses helping in drainage of the sinus. ${ }^{8}$ All beneficial effects are limited by "tachyphylaxis" (Tachyphylaxis refers to the phenomenon of rebound congestion with swelling of nasal mucosa due to rapid desensitization of receptors), hence use must be limited to less than 5 days. ${ }^{8}$

\section{Procedure for the Peak Nasal Flow readings}

Written and verbal consent was obtained prior to the study. Patients were explained that PNF measures how fast a person can breathe through his nose, and this will give information regarding how much of the nose is choked up. Three readings were taken and highest of the three was taken as the data for study.

Mouth piece was cleaned with disinfectant solution (Savlon) and indicator reset to zero.

Patients were asked to breath out of the nose (Peak Nasal Expiratory Flow) or breath in (Peak Nasal Inspiratory Flow) with mouth closed as deep as they could. If they coughed or sneezed during the process, they needed to redo the test.

\section{Statistical analysis}

Student's two-sample " $\mathrm{t}$ " test was used to compare mean PNIF/ PNEF before and after decongestant use in same patient. The tests comprised the comparisons of the ratio of mean regression and mean residual sums of squares to an $\mathrm{F}$ distribution with appropriate degrees of freedom. We used a cut-off of $5 \%$ level as the critical level (meaning 95\% confidence in analysis) of significance in our bio-statistical tests. Maximum value or $\mathrm{C}_{\text {max }}$ and Area under curve were determined for analysis. This was followed by Kaplan-Meier analysis using Bio-statistical graphing software PAST and logrank test and Cox proportion hazard test and $\mathrm{p}$ values were calculated.

\section{Result}

A total of 90 patients met the clinical profile of acute sinusitis and were administered the Peak flowmetry test before and after application of Xylometazoline Nasal spray. (Table I)

A baseline Nasal peak Flowmetry was done and this was followed by nasal decongestant (Xylometazoline $0.1 \%$ solution) spray application, followed by serial 
Table I: Clinical characteristics of acute sinusitis patients included in this study. $(\mathrm{N}=90)$

\begin{tabular}{|c|c|c|}
\hline SL. NO & CLINICAL VARIABLE & DATA \\
\hline 1. & Mean age (range) & 27.8 (15-69) \\
\hline 2. & Sex & Males 48.9\% and females 51.1\% \\
\hline 3. & Height of patient (centimetres) & $\mathbf{1 6 0 . 1 2}($ centimetres) \\
\hline 4. & Smokers & $\mathbf{6 2 . 2 2 \%}$ \\
\hline 5. & Cough & $44.44 \%$ \\
\hline 6. & History of Upper Respiratory tract infection \\
\hline 7. & (Common cold) previously within 10 days & $\mathbf{7 3 . 3 3 \%}$ \\
\hline 8. & Diagnostic endoscopy confirmed & $100 \%$ \\
\hline
\end{tabular}

readings of Nasal peak Flowmetry done after 10, 25, 60, 120, 240 and 360 minutes. Serial time-bound measurement of increase in Nasal peak Flowmetry (mean values) values was done before and after nasal (decongestion) treatment with topical Xylometazoline $0.1 \%$ solution. ${ }^{10}$

It can be inferred from the PNIF/PNEF data that nasal airway increases with time after decongestant application. This is bio-statistically described as classical "Peaked-In" behaviour of a time dependent variable. In our study the flow rates start from a baseline within 10 minutes from application, rise to a peak by an hour, plateau by 2 hours and then slowly return to baseline by 6 hours. (Fig. 1) Maximum value or $\mathrm{C}_{\max }$ of Peak Nasal Inspiratory Flow rate obtained at 1 hour is 170.4 L/min in males and $157.8 \mathrm{~L} / \mathrm{min}$ in females. Area under the curve (AUC) is calculated asunder, using the standard mathematical formula (Trapezium area formula). ${ }^{11}$ (Table II)

Kaplan-Meier Bio-statistical Analysis was done in order to establish and authenticate the time based criteria that are set out by this research. Peak nasal decongestion was taken as survival or 1 for event meaning maximum decongestion achieved 0 for failure or censored. The time for the event was taken on $\mathrm{x}$-axis and probability on y-axis. Plots of Kaplan-Meier curve were generated using PAST (Paleontological statistics software package for education and data analysis). ${ }^{9}$ This was followed by log-rank test and Cox proportion hazard test and $\mathrm{p}$ values were calculated from the table data. (Fig. 2)

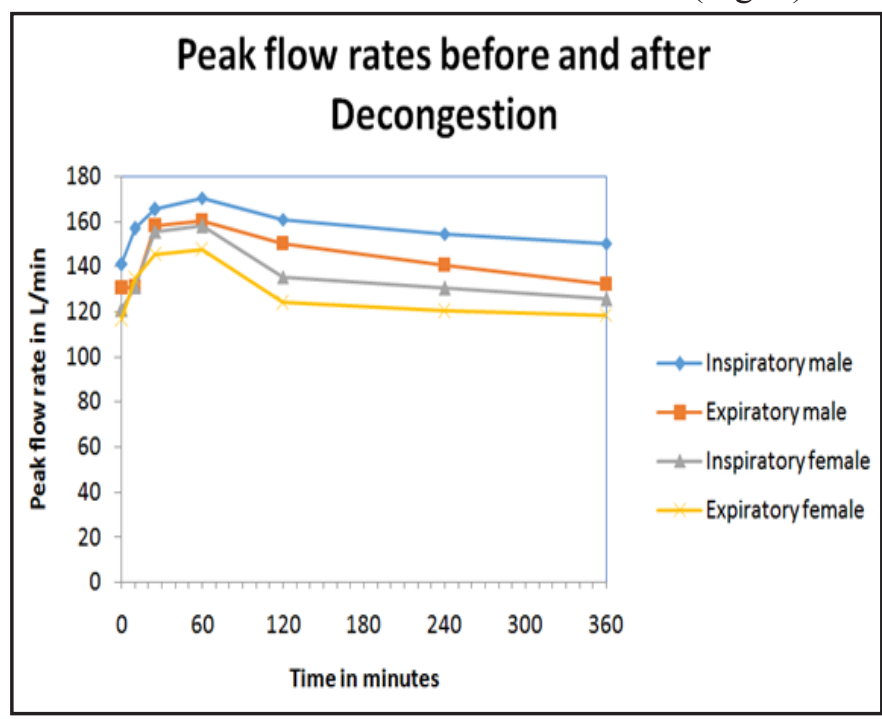

Fig. 1. Plot of Various Mean Peak Flowmetry readings in Acute Sinusitis patients 
Table II: AUC Values for various Curves plotted for Inspiration/ Expiration in male and female

\begin{tabular}{|c|c|c|c|c|}
\hline VARIABLE & $\begin{array}{l}\text { INSPIRATORY } \\
\text { MALE }\end{array}$ & $\begin{array}{l}\text { EXPIRATORY } \\
\text { MALE }\end{array}$ & $\begin{array}{l}\text { INSPIRATORY } \\
\text { FEMALE }\end{array}$ & $\begin{array}{l}\text { EXPIRATORY } \\
\text { FEMALE }\end{array}$ \\
\hline $\begin{array}{l}\text { Area Under Curve (AUC) } \\
\text { Unequal Time Interval study }\end{array}$ & 56889.43 & 52162.8 & 48968.2 & 45560.33 \\
\hline
\end{tabular}

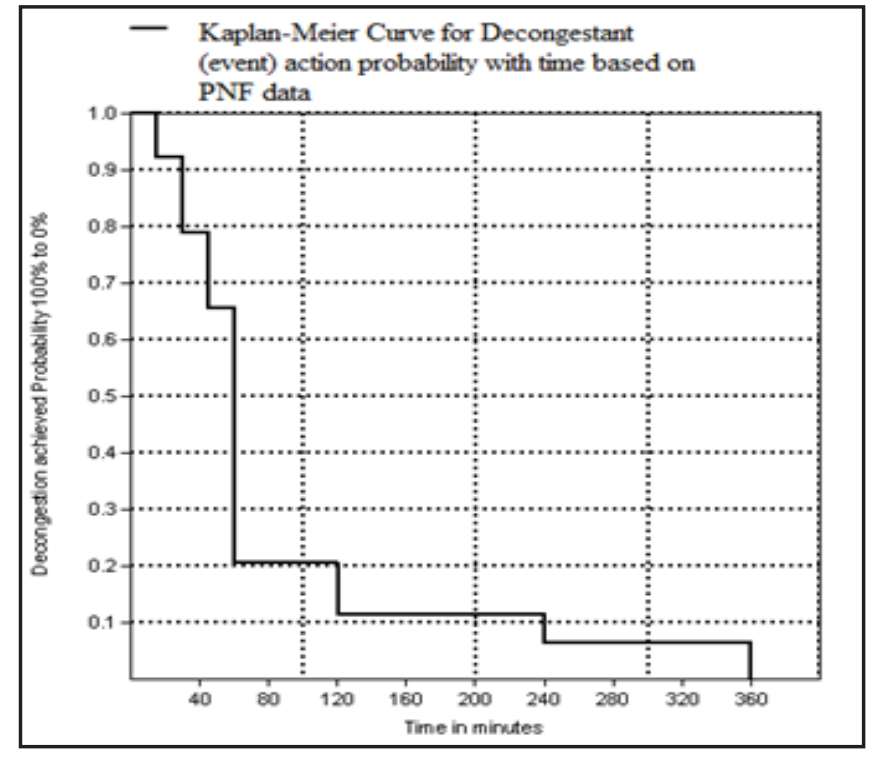

Fig. 2. Kaplan-Meier curve for maximum decongestant action of Xylometazoline $0.1 \%$ solution spray application (event) plotted against time based on Peak nasal flow rate data

Average time to decongest the mucosa was found to be 74.5 minutes ( 1 hour 24 minutes). The log-rank test for the data in our research was $\mathrm{P}=0.0080$; thus the two curves are statistically significantly different. Cox proportion hazard test, ${ }^{11}$ which gives a relative event rate in the groups showed that, Sex and Peak nasal flow rates are strongly correlated except in PEFR of female where their Female sex has not made any statistical difference. (Table III)

\section{Discussion}

Xylometazoline is the work-horse decongestant of Rhinology practice. It is extensively used in management of sinusitis and in peri-operative period by most surgeons. Many prefer to use Xylometazoline with Lignocaine to pack nasal cavity before undertaking nasal surgery. Some advocate its use, up to 5 days before and even after Nasal procedures. Duration of action of nasal decongestant is traditionally thought to be up to 10 hours. $^{3}$

This is the first study in an attempt to quantify the decongestant action of Xylometazoline by using Peak Nasal flow-rate as a tool to measure Nasal airway. This study is rather an objective one with patient providing PNF data without subjective relief being measured.

From the AUC curves it can be inferred that maximum decongestant action of Xylometazoline $0.1 \%$ solution is seen 1 hour after application with a mean time to achieve maximum decongestion being 74.5 minutes ( 1 hour 24 minutes) and the rise in decongestion reaches a plateau by 2 hours. Readings almost return to the baseline at around 6 hours post decongestion.

This fact is clinically reported by patients who frequently claim relief from nasal congestion immediately following use of the spray after which the effect seems to reduce in few hours. Though 8 to 10 hours is mentioned in literature ${ }_{3}$ as average duration of action of Xylometazoline $0.1 \%$ solution, practically the effect does not seem to last more than a couple of hours which can be attested by this research.

\section{Conclusion}

Decongestant action of Xylometazoline $0.1 \%$ solution as quantified by Nasal peak Flowmetry begins within 10 minutes of application and the maximum rise of curve is seen 1 hour (Mean time of 1 hour 24 minutes) after application. Most patients also report relief around 1 to 2 hours after use of the spray.

After 1 hour the effect tapers off to a plateau by 2 hours and 6 hours post application the Nasal peak flow rates almost reach the baseline values. 
Table III: Cox proportion hazard test for Inspiration/ Expiration in male and female

\begin{tabular}{|c|c|c|c|c|}
\hline \multirow{2}{*}{$\begin{array}{c}\text { TEST } \\
\text { STATISTIC }\end{array}$} & $\begin{array}{c}\text { INSPIRATORY } \\
\text { MALE }\end{array}$ & $\begin{array}{c}\text { EXPIRATORY } \\
\text { MALE }\end{array}$ & $\begin{array}{c}\text { INSPIRATORY } \\
\text { FEMALE }\end{array}$ & $\begin{array}{c}\text { EXPIRATORY } \\
\text { FEMALE }\end{array}$ \\
\cline { 2 - 5 } & Hazard ratio & Hazard ratio & Hazard ratio & Hazard ratio \\
\cline { 2 - 5 } $\begin{array}{c}\text { Cox proportion } \\
\text { hazard test }\end{array}$ & 0.58 & 0.61 & 1.44 & 1.71 \\
\cline { 2 - 5 } & p-value & p-value & p-value & p-value \\
\cline { 2 - 5 } & 0.0067 & 0.004 & 0.0032 & 0.321 \\
\cline { 2 - 5 } & significant & significant & significant & Not significant \\
\hline
\end{tabular}

\section{Clinical Application}

Patients who are prescribed Xylometazoline $0.1 \%$ solution are advised that maximum relief would be obtained around 1 to 2 hours after application and thereafter the effect would decrease.

Surgeons who use Xylometazoline $0.1 \%$ solution for nasal packing must proceed with the surgery within 1 hour of application of the pack to obtain maximum haemostatic and decongestant benefit of this drug. Reasonable expected duration of maximum benefit of decongestion from Xylometazoline $0.1 \%$ solution is around an hour to two hours.

\section{References}

1. Corey JP, Houser SM, Ng BA. Nasal congestion: a review of its aetiology, evaluation and treatment. Ear Nose Throat J. 2000; 79: 690-3

2. Holmstrom M. The use of objective measures in selecting patients for septal surgery. Rhinology. 2010; 48: 387-93

3. Clarke RW, Jones AS. The limitations of peak nasal flow measurement. Clinical Otolaryngology Allied Sci. 1994; 19:
$502-4$

4. PDR Physicians' desk reference for non prescription drugs. 19th ed. 1998. Montvale, NJ: Medical Economics Co Inc; 1998. p. 704

5. Pearlman A, Conley D. Review of current guidelines related to the diagnosis and treatment of Rhinosinusitis. Current Opinion in Otolaryngology Head and Neck Surgery 2008; 16:226-30

6. Bende $\mathrm{M}$, fukami $\mathrm{M}$, Arfors KE, Mark $\mathrm{J}$ et al. Effect of oxymetazoline nose drops on acute sinusitis in the rabbit. Annals of Otorhinolaryngology 1996;105:222-5

7. Gillis MC Ed. CPS Compendium of pharmaceuticals and specialties. 34th ed. Ottawa: Canadian Pharmacists Association; 1999. p. 469

8. Lacy CF, Armstrong LL, Ingrim NB, et al. Eds. A Drug information handbook. 6th ed. Cleveland: Lexi-Corp Inc; 1998. p. 764

9. Hammer, Ø., Harper, D.A.T., Ryan, P.D. PAST: Paleontological statistics software package for education and data analysis. Palaeontologia Electronica 2001; 4(1): 9

10. Ottaviano G, Scadding GK, Scarpa B, Accordi D et al. Unilateral peak nasal inspiratory flow, normal values in adult population. Rhinology. 2012; 50: 386-92

11. Guyatt G, Rennie D. User's Guide to Medical Literature: Essentials of Evidence Based Clinical Practice. Chicago, IL: American Medical Association; 2002. 